\title{
HERPESVÍRUS BOVINO TIPO 1 NO SÊMEN
}

\author{
BOVINE HERPESVIRUS-1 IN SEMEN
}

\author{
Maurilio Andrade Rocha ${ }^{1}$ Aurora Maria Guimarães Gouveia ${ }^{2}$ Rômulo Cerqueira Leite ${ }^{1}$
}

\section{- REVISÃO BIBLIOGRÁFICA -}

\section{RESUMO}

O herpesvírus bovino tipo 1 (HVB-1) é o agente causador da rinotraqueíte infecciosa bovina, além de estar associado a doenças do trato genital em bovinos. A transmissão do HVB-1 através da inseminação artificial (IA) pode ocasionar problemas reprodutivos nas vacas inseminadas, como endometrite, infertilidade, absorção embrionária e abortos. Animais infectados tornam-se portadores vitalícios do HVB-1 e podem apresentar episódios intermitentes de reexcreção viral. O HVB-1 poder ser encontrado no sêmen de touros, independente do desenvolvimento de anticorpos neutralizantes. Uma vez que os testes sorológicos não são suficientes para se estimar a presença do HVB-1 no sêmen e que as condições de processamento $e$ armazenamento do sêmen são ideais para a preservação do vírus, somente o exame individual das partidas pode assegurar a comercialização de sêmen livre do vírus. Testes laboratoriais para detecção do HVB-1 no sêmen bovino e medidas adicionais para controlar a transmissão do vírus através da IA são apresentados.

Palavras-chave: rinotraqueite infecciosa bovina, herpesvírus bovino 1, sêmen, latência, inseminação artificial.

\section{SUMMARY}

Bovine herpesvirus $1(B H V-1)$ is the causative agent of infectious bovine rhinotracheitis (IBR) and is also associated with genital disease in cattle. BHV-1 transmission by artificial insemination (AI) may cause reproductive problems in inseminated cows, such as endometritis, infertility, embryonic absorption and abortion. Infected animals are lifelong reservoirs of BHV-1 and may go through intermittent episodes of virus reexcretion. It is important to note that conditions of semen storage are optimal for virus survival. Additionally, BHV-1 can be found in bovine semen despite of the development of neutralizing antibody. Since serological tests are not sufficient to ascertain the presence of the virus in semen, the laboratory testing of all semen batches for $\mathrm{BHV}-1$ is the only way to ensure the BHV-1-free status of the semen for commercialization. Laboratory tests used for BHV-1 detection in bovine semen and additional approaches to prevent the spread of $B H V-1$ through $A I$ are presented.

Key words: infectious bovine rhinotracheitis; bovine herpesvirus 1 , semen, latency, artificial insemination.

\section{INTRODUÇÃO}

O herpesvírus bovino tipo 1 (HVB-1), causador da Rinotraqueíte Infecciosa Bovina (IBR), é membro da família Herpesviridae, subfamília Alphaherpesvirinae. Seu genoma consiste de uma fita dupla de DNA de aproximadamente 137-139 kpb (FIELDS \& KNIPE,1992). Estudos de restrição enzimática possibilitaram a divisão do HVB-1 em três subtipos: HVB-1.1, HVB-1.2a e HVB-1.2b (MILLER et al.,1991). A importância biológica desta classificação não está bem definida, porém uma menor virulência tem sido indicada para o subtipo $2 \mathrm{~b}$, o qual parece não causar aborto, enquanto os subtipos BHV1.1 e BHV1.2a têm sido isolados de fetos bovinos abortados (MILLER $\boldsymbol{e} t$ al.,1991).

A infecção pelo HVB-1 pode resultar em diversas manifestações clínicas, incluindo doença respiratória, vulvovaginite (KENDRICK et al., 1958), balanopostite (STUDDERT $\boldsymbol{e}$ t al., 1964) e diminuição nos índices de fecundação (ELAZHARY et al.,1980). Formas nervosas da doença, há até pouco tempo atribuídas ao HVB-1, são atualmente

\footnotetext{
${ }^{1}$ Médico Veterinário, Doutor, Professor Adjunto, Departamento de Medicina Veterinária Preventiva - Escola de Veterinária da Universidade Federal de Minas Gerais (UFMG).

${ }^{2}$ Médico Veterinário; Doutor, Professor Adjunto, Departamento de Medicina Veterinária Preventiva, Escola de Veterinária, UFMG, CP. 567, 30161-970, Belo Horizonte, Minas Gerais, Brasil. Autor para correspondência. Email: aurora@ vet.ufmg.br
} Recebido para publicação em 01.04.98. Aprovado em 09.12.98 
atribuídas a um tipo diferente de vírus, classificado como herpesvírus bovino tipo 5 ou HVB-5 (ROIZMANN et al., 1992).

A vulvovaginite pustular infecciosa das vacas e a balanopostite infecciosa dos touros já eram reconhecidas na Europa desde antes de 1900, mas a sua importância econômica era subestimada, uma vez que o único sinal clínico detectado era uma breve interferência sobre a eficiência reprodutiva (MILLER et al.,1991). Porém, na década de 1950, pesquisadores americanos reconheceram o papel do HVB-1 como causador também de uma grave infecção do trato respiratório superior de bovinos, a rinotraqueíte infecciosa bovina, conhecida pelas iniciais IBR ("Infectious Bovine Rhinotracheitis"). A enfermidade foi descrita nos EUA pela primeira vez por MILLER (1955), e o primeiro isolamento do vírus a partir de animais com doença respiratória ocorreu naquele país em 1956 (MADIN et al.,1956).

O primeiro isolamento do HVB-1 no Brasil foi realizado em 1978 (ALICE,1978) a partir de pústulas vaginais de vacas no estado da Bahia. No mesmo ano, MUELLER et al. (1978) conseguiram isolar o vírus a partir do rim de um feto bovino proveniente de um matadouro em São Paulo. A partir daí, vários autores vêm relatando a presença do agente em rebanhos bovinos brasileiros com problemas respiratórios, reprodutivos e neurológicos (MUELLER $\boldsymbol{e t}$ al.,1979; GALVÃO,1984; RIETCORRÊA et al.,1989; WEIBLEN et al.,1989; LOVATO et al., 1995a). Os primeiros estudos sorológicos no Brasil foram realizados por GALVÃO et al. (1962/63), que testaram 458 bovinos no estado da Bahia pelo teste de soroneutralização (SN), detectando anticorpos específicos anti-HVB-1 no soro de $34,4 \%$ dos animais. Desde então, diversos autores detectaram sorologicamente a presença do HVB-1 em bovinos de vários Estados da Federação, em percentuais variando entre $18,8 \%$ e $85,7 \%$ (WIZIGMAN et al.,1972; MUELLER et al.,1981; GALVÃO,1984; CASTRO,1988; ANUNCIAÇÃO et al.,1989; RAVAZZOLO et al.,1989; LOVATO et al.,1995b; ROCHA et al.,1995a; FAVA et al., 1997; FILHO et al.,1997).

\section{Latência}

Uma característica marcante do HVB-1, e dos alfaherpesvírus em geral, é sua capacidade de estabelecer latência no hospedeiro. Após a infecção primária, o vírus pode apresentar-se na forma latente nos gânglios sacrais (ACKERMANN \& WYLER,1984; VAN DER ENGELENBURG $\boldsymbol{e}$ al.,1995) e no gânglio trigêmio (SHEFFY \& DAVIES, 1972). A latência é caracterizada pela presença do genoma, ausência de expressão gênica considerável e pela ausência na produção de pro- gênie viral (ENGELS \& ACKERMANN, 1996). Dessa forma, os animais infectados tornam-se portadores vitalícios e podem voltar a eliminar o vírus no sêmen durante episódios de reativação viral. Fatores que causem depressão no sistema imunológico do hospedeiro, como estresse ou tratamento com corticóides, podem afetar o estado de latência e propiciar a reativação da infecção (MILLER \& VAN DER MAATEN,1987; FIELDS \& KNIPE, 1992; MARSI et al.,1996). Mesmo animais clinicamente saudáveis, nos quais a reativação do HVB-1 está ocorrendo, podem apresentar infecções leves ou subclínicas e eliminar grandes quantidades de vírus no sêmen (SNOWDON,1965; VAN DER ENGELENBURG $\boldsymbol{e} t$ al., 1995). Esses achados ressaltam o risco de se utilizar touros soropositivos como doadores de sêmen para IA (SHEFFY \& KRINSKY, 1973).

\section{Excreção viral no sêmen}

Sob condições naturais, os touros são infectados pelas vias aérea ou/e genital. Pequenos nódulos avermelhados na mucosa do prepúcio e do pênis evoluem para pústulas. O pênis torna-se avermelhado e dolorido, podendo o animal apresentar micção freqüente e incapacidade para monta (WEIBLEN,1992). Tem sido postulado que o HVB1 , por replicar predominantemente na mucosa prepucial e na uretra, contamina o sêmen durante a ejaculação, quando o líquido seminal passa sobre as mucosas infectadas. Isto foi confirmado por VAN DER ENGELENBURG et al. (1993) que encontraram mais de $90 \%$ do DNA do HVB-1 no fluido seminal, praticamente não havendo detecção do vírus junto aos espermatozóides.

SNOWDON (1965) isolou o HVB-1 no prepúcio de touros por um período de até 361 dias após infecção experimental. Straub (1967), citado por SPRADBROW (1968), demonstrou que o HVB1 pode estar presente na secreção prepucial de touros em títulos de $10^{8} \mathrm{TCID}_{50} / \mathrm{ml}$, podendo facilmente contaminar o sêmen. VAN DER ENGELENBURG et al. (1995), através do método de PCR, verificaram excreção do HVB-1 no sêmen de touros por um período de até 65 dias após infecção experimental. MARSI et al. (1996) detectaram o HVB-1 no sêmen de quatro touros através de PCR por até 18 dias após a infecção experimental primária e por até 14 dias após a reativação experimental da infecção. XIA $\boldsymbol{e t}$ al.(1995b), utilizando PCR, detectaram o vírus em sêmen de touros até 40 dias após a inoculação experimental pela via intraprepucial.

\section{Resistência do vírus no sêmen \\ O HVB-1 é o patógeno viral mais fre- qüentemente encontrado no sêmen bovino}


(AFSHAR \& EAGLESOME,1990) e sua transmissão tem sido amplamente favorecida pelo desenvolvimento de processos de criopreservação do sêmen, uma vez que as condições de processamento e armazenamento do sêmen são ideais para a preservação do HVB-1. A infectividade do HVB-1 no sêmen pode permanecer conservada por até sete dias em temperatura de $4^{\circ} \mathrm{C}$ e por cinco dias em temperatura ambiente (DREW $\boldsymbol{e}$ t $\boldsymbol{a l}$. 1987). CHAPMAN $\boldsymbol{e}$ t $\boldsymbol{a l}$. (1979) demostraram, através do isolamento em cultivo celular e quantificação, não haver perda no título do HVB-1 em sêmen bovino armazenado por mais de um ano em nitrogênio líquido. SPRADBROW (1968), examinando o sêmen de 40 touros provenientes de três centrais de sêmen australianas, isolou o HVB-1 em três ampolas provenientes de uma mesma coleta e descongeladas em épocas diferentes, utilizando cultivo celular de rim bovino. Após 12 meses de armazenamento, o vírus ainda estava presente em uma das amostras na concentração de $10^{4.3} \mathrm{TCID}_{50} / \mathrm{ml}$.

\section{Soropositividade}

Não existe uma correlação obrigatória entre a presença de infecção pelo HVB-1 e a detecção de anticorpos específicos circulantes, uma vez que tem sido relatada a detecção do HVB-1 em amostras clínicas obtidas de animais soronegativos (HUCK, 1971; PARSONSON \& SNOWDON, 1975; KUPFERSCHIMIED et al.,1986; XIA et al.,1995a; GEE et al.,1996). SCHULTZ et al. (1976) citam três possibilidades em que o vírus pode ser detectado no sêmen de touros soronegativos: a) animais susceptíveis com infecção ativa e excretando o vírus antes do desenvolvimento de anticorpos ; b) baixa sensibilidade do teste em detectar reduzidos níveis de anticorpos; c) alguns animais infectados podem desenvolver a imunidade celular sem resposta humoral mensurável. Desta forma, apesar de ser um importante instrumento para detecção de infecção, a pesquisa de anticorpos constitui-se em uma forma incompleta de se determinar a presença do HVB-1 no sêmen.

O uso generalizado de vacinas convencionais anti-HVB-1 não parece ter reduzido a prevalência da infecção. Por outro lado, um grande número de animais soropositivos tem sido detectado nos testes sorológicos, sem poder ser realizada a diferenciação entre animais infectados e vacinados. Vacinas marcadas permitem essa diferenciação e parecem ser mais indicadas, principalmente para uso em touros de centrais e em programas de erradicação do HVB1 (FLORES $\boldsymbol{e}$ t al., 1993; VAN OIRSCHOT $\boldsymbol{e}$ t al., 1996).

\section{Infecção em touros de centrais de IA}

BOECKX et al. (1968) detectaram o

HVB-1 em touros de uma central de IA localizada na Bélgica, através de testes de isolamento e neutralização viral. Os autores verificaram que os animais inseminados com sêmen dessa central apresentavam baixas taxas de concepção. KNOBLAUCH (1962) não verificou interferência sobre as taxas de concepção ou sobre a qualidade do sêmen obtido de touros soropositivos ao HVB-1 de uma central de IA. HUCK (1971) isolou o HVB-1 a partir de "swab" prepucial de 4 touros de uma central de IA, sendo que um destes animais apresentava sorologia negativa no momento do isolamento viral. GÓLAN et al.(1990) realizaram estudos sobre a infecção pelo HVB-1 em touros alojados em centrais de sêmen, localizadas na província de Santa Fé, Argentina. Os autores isolaram e identificaram o HVB-1 como causador de efeito citopático (ECP) em sete dentre 40 amostras estudadas. VAN OIRSCHOT et al. (1993), estudando uma central de sêmen holandesa na qual nenhum sinal clínico de IBR havia sido observado, verificaram que pelo menos 75 touros de um total de 116 examinados apresentavam infecção subclínica pelo HVB-1, sendo o vírus isolado de 43 amostras de sêmen destes animais. Os autores verificaram eliminação intermitente do vírus no sêmen. GEE et al.(1996) relataram um surto de infecção pelo HVB-1 em touros de uma central de IA holandesa supostamente negativa para HVB-1. Dois animais mostraram sinais clínicos de IBR, tendo o HVB-1 sido detectado em "swab" nasal através de PCR. Subseqüentemente, o DNA do vírus foi detectado através de PCR em "swabs" nasais provenientes de outros 23 animais. Tem sido também relatada a infecção pelo HVB-1 em touros alojados em centrais de IA localizadas em diversos países, como África do Sul (MARÉ, 1961), Alemanha (STRAUB \& MÄCKLE,1965), Austrália (SPRADBROW, 1968), Dinamarca (AUTRUP \& BITSCH, 1978), Noruega (SAXEGAARD, 1966) e Suíça (BRUNNER et al.,1988).

WEIBLEN et al.(1991) descreveram isolamentos de HVB-1 em sêmen e "swabs" prepuciais de touros de uma central de IA brasileira, onde alguns animais vieram a apresentar sinais clínicos em um período de 13 dias após o primeiro isolamento. ROCHA et al. (1995a, 1997) detectaram infecção subclínica pelo HVB-1 em touros de uma central brasileira de IA. Os autores detectaram anticorpos específicos em $60,7 \%$ dos touros examinados através de testes de soroneutralização, verificando-se inclusive um caso de soroconversão, além de terem isolado o vírus em 20 dentre 101 amostras de sêmen, sem que nenhum touro apresentasse sintomatologia clíni- 
ca. PITUCO (1988) detectou anticorpos específicos em $72,5 \%$ de 131 touros alojados em centrais de IA em São Paulo, Minas Gerais e Rio Grande do Sul, através de testes de soroneutralização. PASSOS $\boldsymbol{e t}$ al. (1992) não observaram soroconversão nem isolaram o vírus do sêmen de touros soropositivos alojados em uma central brasileira de IA, durante dois anos de estudo.

\section{Efeitos do uso de sêmen contaminado sobre a reprodução}

A inseminação artificial com sêmen contaminado pode ocasionar sérias perdas reprodutivas às vacas inseminadas. KENDRICK \& McENTEE (1967), inseminando 12 vacas com sêmen artificialmente contaminado pelo HVB-1, detectaram 10 vacas com endometrite, lesões nos ovidutos e encurtamento do ciclo estral (abaixo de 18 dias). Cinco animais apresentaram encistamento do corpo lúteo, sendo que 11 vacas falharam na concepção. WHITE \& SNOWDON (1973) examinaram taxas de fertilidade em 149 vacas de 20 rebanhos. Animais inseminados com sêmen contaminado pelo HVB-1 apresentaram taxa de não retorno ao serviço de $13,4 \%$ comparada com uma taxa de $60,8 \%$ quando sêmen não contaminado foi utilizado. Das vacas que retornaram ao serviço, 22,1\% apresentaram encurtamento do ciclo estral (<18dias). PARSONSON \& SNOWDON (1975), utilizando sêmen livre e contaminado pelo HVB-1 e também touros livres e contaminados pelo vírus, observaram baixa taxa de fecundação (40\%) e necessidade de 4,5 serviços por concepção no grupo de vacas que recebeu sêmen contaminado através da IA, em comparação aos outros grupos. Entre as vacas do grupo que apresentou baixa taxa de concepção, $28 \%$ dos animais exibiram encurtamento do ciclo estral e sinais clínicos de vulvovaginite pustular infecciosa (VPI). Vacas cobertas naturalmente por touros infectados apresentaram sinais clínicos de VPI e uma taxa de concepção de $89 \%$, com baixa interferência na fertilidade; as cobertas por touros normais apresentaram taxa de concepção de $100 \%$, sem nenhum sinal clínico. ELAZHARY et al (1980) isolaram o HVB-1 do conteúdo uterino de oito vacas de um grupo de 11 animais com baixa taxa de prenhez e alto número de serviços por concepção. O touro utilizado no programa de reprodução do plantel eliminava o vírus no sêmen. MILLER \& VAN DER MAATEN (1984) observaram endometrite necrótica, corpo lúteo cístico, necrose focal do corpo lúteo em novilhas inoculadas com HVB-1 pela via intra-uterina. KUPFERSCHIMIED et al.(1986) relataram a contaminação de vacas através da inseminação com sêmen importado, contaminado pelo vírus, proveni- ente de touro soronegativo. As vacas inseminadas apresentaram taxas de não retorno ao cio $10 \%$ abaixo da média do rebanho, além de soroconversão. O risco de transmissão da doença através da transferência de embriões parece ser de menor importância (PHILPOTT, 1993).

\section{Detecção laboratorial do vírus no sêmen}

O isolamento viral em cultivo de células é o método laboratorial de diagnóstico mais utilizado para a detecção do HVB-1 no sêmen (AFSHAR \& EAGLESOME, 1990). DREW et al. (1987) conseguiram detectar 1 TCID $_{50}$ de HVB-1 em sêmen artificialmente contaminado. Segundo os autores, o cultivo em microplacas de 24 cavidades se mostrou mais adequado do que o cultivo em tubos Leighton para o estudo de grandes quantidades de amostras. $\mathrm{O}$ isolamento viral a partir de sêmen pode apresentar algumas dificuldades, como citotoxicidade, contaminação bacteriana, (DARCEL \& COULTER, 1976; ROCHA et al., 1995b) e perda da capacidade infectiva do material durante a coleta, diluição e processamento da amostra (FLORES \& WEIBLEN, 1989). A diluição do sêmen antes da inoculação no cultivo vem apresentando bons resultados no sentido de se eliminar os efeitos tóxicos do sêmen sobre os cultivos celulares (LOEWEN \& DARCEL, 1985). BRUNNER et al. (1988) conseguiram detectar 5 $\mathrm{TCID}_{50} / 0,5 \mathrm{ml}$ de sêmen artificialmente contaminado pelo HVB-1, utilizando a pré-diluição do sêmen.

A técnica da reação da polimerase em cadeia (PCR) vem sendo apontada como uma alternativa para a detecção laboratorial de diversos microrganismos (BELAK \& BALLAGI-PORDÁNY, 1993). Recentes pesquisas vêm sendo desenvolvidas com o objetivo de se estabelecer uma PCR sensível e rápida na detecção do HVB-1 em sêmen, para uso na rotina laboratorial. VAN DER ENGELENBURG $\boldsymbol{e} \boldsymbol{t}$ al.(1993), YASON et al., (1995) e ROCHA et al., (1998) obtiveram sensibilidade de $0,05 \mathrm{TCID}_{50} / 50 \mu \mathrm{l}$, $1 \mathrm{TCID}_{50} / 50 \mu \mathrm{l}$ e $0,001 \mathrm{TCID}_{50} / 50 \mu \mathrm{l}$ em seus testes, respectivamente. Por ser um teste bastante sensível, procedimentos rigorosos de controle são recomendados para se evitar contaminações durante a realização da PCR (KWOK,1990).

\section{Medidas de controle}

A infecção pelo HVB-1 torna-se mais crítica em touros reprodutores de centrais de sêmen, uma vez que o vírus permanece viável no sêmen congelado e pode ser distribuído para diversas propriedades que utilizam programas de inseminação artificial. Uma vez demostrado que nem todas coletas de sêmen de um animal estão necessariamente contaminadas, somente o exame individual das par- 
tidas coletadas pode assegurar que o sêmen a ser comercializado é livre de HVB-1, mesmo quando obtido de touros infectados (SHEFFY et al.,1973; KUPFERSCHIMIED et al.,1986; AFSHAR \& EAGLESOME,1990). SHEFFY et al.(1973) recomendam, como medidas de controle nas centrais de coleta de sêmen, o recrutamento de touros soronegativos sempre que possível; manutenção de touros soropositivos sob condições livres de estresse; cuidadosa observação clínica para sinais de recrudescência e teste das coletas de sêmen suspeitas de contaminação pelo HVB-1. SCHULTZ et al. (1976) recomendam não coletar sêmen de touros com sinais de IBR, não tratar animais soropositivos com corticóides e mantê-los em situações de baixo estresse. KUPFERSCHIMIED $\boldsymbol{e t}$ al. (1986) recomendam novo exame sorológico para touros exportadores de sêmen quatro a seis semanas após a coleta, e antes da comercialização do sêmen. AFSHAR \& EAGLESOME (1990) recomendam somente coletar sêmen de touros soropositivos quando estes não estiverem apresentando sinais clínicos de IBR; testar número representativo de amostras de sêmen de cada dia de coleta para a presença do HVB-1; liberar o sêmen congelado para inseminação somente após a confirmação do estado negativo e, principalmente, tentar estabelecer um plantel livre de anticorpos para o HVB-1. O uso de vacinas marcadas tem sido indicado para permitir diferenciação entre anticorpos induzidos por vacinação ou por infecção natural (KAASHOEK et al., 1995). Segundo GEE $\boldsymbol{e t}$ al.(1996) todos os touros alojados em centrais de inseminação artificial oficialmente aprovadas pela Comunidade Européia devem ser soronegativos para o HVB-1, devido ao fato de os animais infectados se tornarem portadores vitalícios do vírus.

\section{CONCLUSÃO}

A infecção pelo herpesvírus bovino 1 pode ocasionar importantes perdas reprodutivas em bovinos, principalmente quando transmitida através da inseminação artificial. Uma vez que os touros com infecção latente podem voltar a eliminar o vírus no sêmen durante episódios de reativação viral e que as condições de processamento e estocagem do sêmen são ideais para a preservação do HVB-1, tornase desaconselhável o uso de touros soropositivos como doadores de sêmen. Alternativamente, medidas adicionais de manejo devem ser empregadas nesses animais. A vacinação de touros doadores de sêmen deve ser evitada, porém, se adotada, devem ser utilizadas vacinas anti-HVB-1 com marcadores antigênicos, por permitirem a diferenciação entre animais vacinados e naturalmente infectados. A associação entre detecção laboratorial de amostras de sêmen contaminadas pelo HVB-1 e a adoção de medidas adicionais de manejo dos touros doadores de sêmen pode contribuir substancialmente para o controle da transmissão do HVB-1 através da inseminação artificial. Apenas o exame individual das partidas de sêmen coletadas para a presença do vírus pode assegurar a comercialização de sêmen livre de HVB-1.

\section{REFERÊNCIAS BIBLIOGRÁFICAS}

ACKERMANN, M., WYLER, R. The DNA of na IPV strain of bovid herpesvirus 1 in sacral ganglia during latency after intravaginal infection. Veterinary Microbiology, v. 9, n. 1, p. 53-63, 1984.

AFSHAR, A., EAGLESOME, M.D. Viruses associated with bovine semen. Veterinary Bulletin, v. 60, n. 2, p. 93-109, 1990.

ALICE, F.J. Isolamento do vírus da rinotraqueíte infecciosa bovina (IBR) no Brasil. Revista Brasileira de Biologia, v. 38, n. 4 , p. $919-920,1978$

ANUNCIAÇÃO, A.V.M., MOREIRA, E.C., LEITE, R.C., $\boldsymbol{e} \boldsymbol{t} \boldsymbol{a l}$. Presença de anticorpos para o herpesvírus bovino 1 (HVB-1) em bovinos nos estados de Minas Gerais, Goiás e Rio de Janeiro, através da prova de hemoaglutinação passiva. Arquivo Brasileiro de Medicina Veterinária e Zootecnia, v. 41, n. 5, p. 433-441, 1989.

AUTRUP, E.H., BITSCH, V. The occurrence, control and eradication of infectious bovine rhinotracheitis virus infection at artificial insemination centres in Denmark. Nordisk Veterinaermedicin, v. 30, n. 4-5, p. 169-177, 1978.

BELÁK, S., BALLAGI-PORDÁNY, A. Application of the polymerase chain reaction (PCR) in veterinary diagnostic virology. Veterinary Research Communications, v. 17, n. 1, p. 55-72, 1993.

BOECKX, M. IBRAHIM, M., BOUTERS, R. De invloed van een acute IPV/IBR incetie op de bevruchtingsresultaten van K.I. stieren. Vlaams Diergereeskunding Tijdschrift, v. 37, p. 177-188, 1968.

BRUNNER, D., ENGELS, M., SCHWYZER, M., et al. A comparison of three techniques for detection of bovine herpesvirus type 1 (BHV-1) in naturally and experimentally contaminated bovine semen. Zuchtygiene, v. 23, n. 1, p. 1-9, 1988 .

CASTRO, R. S. Desempenho reprodutivo até 60 dias de gestação em doadoras de embriões bovinos, frente à infecção por diarréia bovina a vírus, herpesvírus bovino tipo 1, leucose bovina e língua azul, em Minas Gerais. Belo Horizonte, MG. 93p. Dissertação (Mestrado em Medicina Veterinária Preventiva e Epidemiologia) - Curso de Pósgraduação em Medicina Veterinária Preventiva e Epidemiologia, Universidade Federal de Minas Gerais,1988.

CHAPMAN, M.S., LUCAS, M.H., HEBERT, C.N., et al. Survival of infectious bovine rhinotracheitis virus in stored bovine semen. Veterinary Sciences Communications, v. 3, n. 2, p. 137-139, 1979. 
DARCEL, CE le Q., COULTER, G.H. IBR virus neutralizing substance in bull seminal fluid and its removal prior to attempts at virus isolation from semen. Canadian Veterinary Journal, v. 17, n. 12, p. 318-320, 1976.

DREW, T.W., HEWITT-TAYLOR, C., WATSON, L., $\boldsymbol{e}$ t al. Effect of storage conditions and culture technique on the isolation of infectious bovine rhinotracheitis virus from bovine semen. Veterinary Record, v. 121, n. 23, p. 547-548, 1987.

ELAZHARY, M.A.S.Y., LAMOTHE, P. , SILIM, A., $\boldsymbol{e} \boldsymbol{t}$ al. Bovine Herpesvirus type 1 in the sperm of a bull from a herd with fertility problems. Canadian Veterinary Journal, v. 21, n. 12 , p. $336-339,1980$

ENGELS, M., ACKERMANN,M. Pathogenesis of ruminant herpesvirus infections. Veterinary Microbiology, v. 53, n. 12, p. 3-15, 1996.

FAVA, C., PITUCO, E.M., STEFANO, E., et al. Monitoramento sorológico do HVB-1 em rebanho bovino leiteiro. In:CONGRESSO BRASILEIRO DE MEDICINA VETERINÁRIA, 25. Gramado, Sociedade de Veterinária do Rio Grande do Sul, 20 a 24 out. 1997. Anais... Gramado, Sociedade de Veterinária do Rio Grande do Sul, 1997, p. 289.

FIELDS, B.N., KNIPE, D.M. Virology, New York: Raven Press, 1992, 2 v., 2419 p.

FILHO, I.R.B., KRÜGER, E.R., SOUZA, J.F., et $\boldsymbol{a l}$. Incidência de bovinos soropositivos para o vírus da rinotraqueíte bovina no município de Palotina-PR. In: CONGRESSO BRASILEIRO DE MEDICINA VETERINÁRIA, 25. Gramado, Sociedade de Veterinária do Rio Grande do Sul, 20 a 24 out. 1997. Anais... Gramado, Sociedade de Veterinária do Rio Grande do Sul, 1997, p. 171.

FLORES, E.F., WEIBLEN, R. Agentes virais presentes no sêmen bovino. A Hora Veterinária. v. 9, n. 50, p. 43-46, 1989.

FLORES, E.F., OSORIO, F. A, ZANELLA, E.L., et al. Efficacy of a deletion mutant bovine herpesvirus-1 (BHV-1) vaccine that allows serologic differentiation os vaccinated from naturally infected animals. Journal of Veterinary Diagnostic Investigation, v. 5, n. 4, p. 534-540, 1993.

GALVÃO, C.L. Diagnóstico da infecção genital do herpesvírus bovino 1 (HVB-1) pelos métodos de isolamento e imunofluorescência direta. Belo Horizonte, MG. 93 p. Dissertação (Mestrado em Medicina Veterinária Preventiva e Epidemiologia) - Curso de Pós-graduação em Medicina Veterinária Preventiva e Epidemiologia, Universidade Federal de Minas Gerais, 1984.

GALVÃO, C.L., DÓRIA, J.D., ALICE, F.J. Anticorpos neutralizantes para o vírus da rinotraqueíte infecciosa dos bovinos em bovinos do Brasil. Boletim do Instituto Biológico da Bahia, v. 6, n. 1, p. 15-25, 1962/1963.

GEE, A.L.W., WATGER, L.H.A., HAGE, J.J. The use of a polymerase chain reaction assay for the detection of bovine herpesvirus 1 in semen during a natural outbreak of infectious bovine rhinotracheitis. Veterinary Microbiology, v. 53, n. 12, p. 163-168, 1996.

GÓLAN, A.E., SCORTTI, M., OCCHI, H., et al. Detection of bovine herpesvirus type 1 in frozen semen and aborted foetuses in Santa Fe Province, Argentina. Avances En Ciencias Veterinarias, v. 5, n. 2, p. 142-145, 1990.
HUCK, R.A. MILLAR, P.G., EVANS, D.H., et al. Penoposthitis associated with infectious bovine rhinotracheitis/infectious pustular vulvovaginitis (IBR/IPV) virus in a stud of bulls. Veterinary Record. v. 88, p. 292-297, 1971

KAASHOEK, M.J., MOERMAN, A., MADIC, J., et al. An inactivated vaccine based on a glycoprotein E-negative strain of bovinr herpesvirus 1 induces protective immunity and allows serological differentiation. Vaccine, v. 13, p. 342-346, 1995 .

KENDRICK, J.W. , McENTEE, K. The effects of artificial insemination with semen contaminated with IBR-IPV virus. Cornell Veterinarian, v. 57, n. 1, p. 3-11, 1967.

KENDRICK, J.W., GILLESPIE, J.H., McENTEE, K. Infectious pustular vulvovaginitis of cattle. Cornell Veterinarian. v. 48 , n. 4, p. 458-495, 1958.

KNOBLAUCH, H. Der virus-blaerschenausschlag des rindes als massenerkrankung auf einer besamungsstation. Monatshefte fur Veterinärmedizin, v. 17, p. 445-450, 1962.

KUPFERSCHIMIED, H.U., KIHM, U., BACHMAN, P., $\boldsymbol{e}$ t al. Transmission of IBR/IPV virus in bovine semen: a case report. Theriogenology, v. 25, n. 3, p. 439-443, 1986.

KWOK, S. Procedures to minimize PCR-product carry-over. IN PCR protocols: $A$ guide to methods and applications. INNIS, M.A.,GELFAN, D.H., SNINSKY, J.J., WHITE, T.J.. San Diego: Academic Press, 1990. 482 p.

LOEWEN, K.G., DARCEL, C. le Q. A comparison of two methods for the isolation of bovine herpesvirus 1 (BHV-1) from extended bovine semen. Theriogenology, v. 23, n. 6, p. 935-943, 1985.

LOVATO, L.T., WEIBLEN, R., RABUSKE,M., $\boldsymbol{e}$ t $\boldsymbol{a}$. Herpesvírus bovino tipo 1: Isolamento de casos de vulvovaginite. Semina. v. 16, n. 1, p. 156-157, 1995a.

LOVATO, L.T., WEIBLEN, R., MORAES, M.P., et al. Herpesvírus bovino tipol (HVB-1): inquérito soroepidemiológico no rebanho leiteiro do Estado do Rio Grande do sul. Ciência Rural, v. 25, n. 3, p. 425-430, 1995b.

MADIN, S.H., YORK, C.J., MCKERCHER, D.G. Isolation of infectious bovine rhinotracheitis virus. Science, v. 124, n. 3225 , p. 721-722, 1956

MARÉ, C.J., VAN RENSBURG, S.J. The isolation of viruses associated with infertility in cattle: a preliminary report Journal of South African Veterinary Medical Association, v. 32, p. 201-210, 1961

MARSI, S.A., OLSON,W., NGUYEN, P.T. et al. Rapid detection of bovine herpesvirus 1 in semen of infected bulls by a nested polymerase chain reaction. Canadian Journal of Veterinary Research, v. 60, n. 2, p. 100-107, 1996.

MILLER, J.M., VAN DER MAATEN, M.J. Reproduction tract lesions in heifers after intrauterine inoculation with infectious bovine rhinotracheitis virus. American Journal of Veterinary Research , v. 45, n. 4, p. 790-794, 1984.

MILLER, J.M.,VAN DER MAATEN, M.J. Early embrionic death in heifers after inoculation with bovine herpesvirus-1 and reactivation of latent virus in reproductive tissues. American Journal Veterinary Research, v. 48, n. 11, p. 1555-1558, 1987. 
MILLER, J.M., WHETSTONE, C.A., VAN DER MAATEN, M.J. Abortifacient property of bovine herpesvirus type 1 isolates that represent three subtypes determined by restriction endonuclease analysis of viral DNA. American Journal of Veterinary Research. v. 52, n. 3,p. 458-461, 1991.

MILLER, N.J. Infectious necrotic rhinotracheitis of cattle. Journal of American Veterinary Medical Association, v. 126, n. 939, p. 463-467, 1955.

MUELLER, S.B.K., IKUNO, A.A., CAMPOS, M.T.G.R., et al. Isolamento e identificação do vírus da rinotraqueíte infecciosa dos bovinos de um rim de feto de bovino (IPV/IBR). Arquivos do Instituto Biológico, v. 45, n. 3, p.187-190, 1978

MUELLER, S.B.K., IKUNO, A.A., CAMPOS, M.T.G.R., et al. Ocorrência simultânea de alterações respiratórias e genitais associada à rinotraqueíte infecciosa dos bovinos/vulvovaginite pustular infecciosa (IBR/IPV) em um rebanho no estado de São Paulo. Biológico, v. 45, n. 3-4, p. 55-60, 1979.

MUELLER, S.B.K., IKUNO, A.A., MACHADO, J.S. et al. Prevalência de anticorpos contra o vírus da rinotraqueíte infecciosa dos bovinos/ vulvovaginite pustular infecciosa (IBR/IPV) em bovinos do estado de São Paulo. Biológico, v. 47 , n. 2 , p. $55-59,1981$

PARSONSON, I.M., SNOWDON, W.A. The effect of natura and artificial breeding using bulls infected with or semen contaminated with IBR virus. Australian Veterinary Journal, v. 51, n. 8, p. 365-369, 1975.

PASSOS, E.C., DE STEFANO, E., PITUCO, E.M., $\boldsymbol{e}$ t al. Pesquisa do vírus da rinotraqueíte infecciosa/vulvovaginite pustular infecciosa (IBR/IPV) em sêmen e swab prepucial e estudo da persistência de anticorpos em touros doadores. Revista Brasileira de Reprodução Animal, v. 16, n. 3-4, p 87-93, 1992.

PHILPOTT, M. The dangers of disease transmission by artificial insemination and embryo transfer. British Veterinary Journal, v. 149, n. 4, p. 339-369, 1993

PITUCO, E.M. Ocorrência da rinotraqueíte infecciosa dos bovinos/vulvovaginite pustular infecciosa (IBR/IPV) em rebanhos bovinos criados nos estados de São Paulo, Rio Grande do Sul, Paraná e Minas Gerais. Utilização das reações sorológicas de microssoroneutralização, microhemoaglutinação passiva e da imunofluorescência indireta para detecção de anticorpos anti-herpesvírus bovino-1. São Paulo, SP. 74 p. Dissertação (Mestrado em Patologia Bovina) - Faculdade de Medicina Veterinária e Zootecnia, USP, 1988.

RAVAZZOLO, A.P., PIZZOL, M.P., MOOJEN, V. Evidência da presença de anticorpos para o vírus da rinotraqueíte infecciosa dos bovinos em bovinos de alguns municípios do estado do Rio Grande do Sul, Brasil 1986. Arquivos da Faculdade de Veterinária da UFRGS, v. 17, p. 89-95, 1989.

RIET-CORRÊA, F., VIDOR, T., SCHILD, A.L., et al. Meningoencefalite e necrose da córtex cerebral em bovinos causadas por herpesvírus bovino-1. Pesquisa Veterinária Brasileira, v. 9, n. 1-2, p. 13-16, 1989.

ROCHA, M.A., GOUVEIA, A.M.G., LEITE, R.C. Detecção de anticorpos para o herpesvírus bovino-1 em touros de uma central de sêmen. Revista Brasileira de Reprodução Animal, v. 19, n. 3-4, p. 181-186, 1995a.
ROCHA, M.A., GOUVEIA, A.M.G., LEITE, R.C. La técnica del cultivo celular en microplacas en el aislamiento del virus herpes bovino tipo 1 en semen bovino. Avances en Ciencias Veterinarias, v. 10, n. 2, p. 134-135, 1995b.

ROCHA, M.A., GOUVEIA, A.M.G., LEITE, R.C., $\boldsymbol{e} t \boldsymbol{a l}$. Isolamento do herpesvírus bovino-1 (HVB-1) em sêmen de touros de uma central brasileira de inseminação artificial. Revista Brasileira de Reprodução Animal, v. 21, n. 2, p. 162-163, 1997.

ROCHA, M.A., BARBOSA, E.F., DIAS NETO, E., et al. A high sensitivity nested PCR assay for BHV-1 detection in semen of naturally infected bulls. Veterinary Microbiology, v. 63, n. 1, p. 1-11, 1998 .

ROIZMANN, B., DESROSIERS, R.C., FLECKENSTEIN, B. t al. The family Herpesviridae: an update. The Herpesvirus Study Group of the International Committee on Taxonomy of Viruses. Archives of Virology, v. 123, n. 3-4, p. 425-449, 1992.

SAXEGAARD, F. Problems connected with the diagnosis of subclinical infectious pustular vulvovaginitis virus (IPV virus) in bulls. Nordisk Veterinaermedicin, v. 18, p. 452-459, 1966.

SCHULTZ, R.D., HALL, C.E., SHEFFY, B.E., et al. Current status of IBR/IPV virus infection in bulls. Proceedings of the United States Animal Health Association, v. 80, P. 159-168, 1976.

SHEFFY, B.E., DAVIES, D.H. Reactivation of a bovine herpesvirus after costicosteroid treatment. Proceedings of the Society for Experimental Biology and Medicine, v. 140, p. 974-976, 1972.

SHEFFY, B.E., KRINSKY, M. Infectious bovine herpesvirus in extended bovine semen. Proceedings of the United States animal Health Association, v. 77, p. 131-137, 1973

SNOWDON, W.A. The IBR/IPV virus-reaction to infection and intermittent recovery of the virus from experimentally inoculated cattle. Autralian Veterinary Journal, v. 41, n. 5, p. $135-142,1965$.

SPRADBROW, W.A. The isolation of infectious bovine rhinotracheitis virus from bovine semen. Australian Veterinary Journal, v. 44, n. 9, p. 410-412, 1968.

STRAUB, O.C., MÄCKLE, n. Ein Ausbruch des Blaeschenausschlages in einer Besamungsstation. Tierärtzliche Umschau, v. 20, p. 113-116, 1965.

STUDDERT, M., BARKER, C.A., SAVAN, M. Infectious pustular vulvovaginitis virus infection in bulls. American Journal Veterinary Research, v. 25, n. 105, p. 303-314, 1964.

VAN DER ENGELENBURG, F.A.C., MAES, R.K., VAN DER OIRSCHOT, J.T, et al. Development of a rapid and sensitive polymerase chain reaction assay for detection of bovine herpesvirus type 1 in bovine semen. Journal of Clinical Microbiology, v. 31, n. 12, p. 3129-3135, 1993.

VAN DER ENGELENBURG, F.A.C., VAN SCHIE, F.W., RIJSEWIJK, F.A.M., et al. Excretion of bovine herpesvirus 1 in semen is detected much longer by PCR than by virus isolation. Journal of Clinical Microbiology, v. 33, n. 2, p. 308-312, 1995. 
VAN OIRSCHOT, J.T., STRAVER, P.J., LIESHOUT, J.A.M., et al. A subclinical infection of bulls with bovine herpesvirus type 1 at an artificial insemination centre. Veterinary Record, v. 132, n. 2, p. 32-35, 1993.

VAN OIRSCHOT, J.T., KAASHOEK, M.J., RIJSEWIJK, F.A Advances in the development and evaluation of bovine herpesvirus 1 vaccine. Veterinary Microbiology, v. 53, n. 12, p. 43-54, 1996

WEIBLEN, R., LOMBARDO DE BARRROS, C.S., CANABARRO, T.F., et al. Bovine meningoencephalitis from IBR virus. Veterinary Record, v. 124, n. 25, p. 666-667, 1989.

WEIBLEN, R. Doenças víricas que interferem na produção leiteira. In: CHARLES, T.P. , FURLONG. Doenças dos bovinos de leite adultos, Coronel Pacheco: EMBRAPACNPGL, 1992, 174p.

WEIBLEN, R., KREUTZ, L.C., CANABARRO, T.F., et al. Balanoposthitis in bulls due to bovine herpesvirus in South Brasil. Brazilian Journal of Medical and Biological Research, v. 24, n. 8, p. 773-775, 1991.

WHITE, M.B., SNOWDON, W.A. The breeding record of cows inseminated with a batch of semen contaminated with infectious bovine rhinotracheitis virus. Australian Veterinary Journal, v. 49, n. 11, p. 501-506, 1973.

WIZIGMANN, G., VIDOR, T., RICCI, Z. M.F. Investigação sorológica sobre a incidência e ocorrência dos vírus PI-3, IBR e da diarréia a vírus/enfermidade das mucosas dos bovinos no estado do Rio Grande do Sul. Boletim do Instituto de Pesquisas Veterinárias Desidério Finamor, v. 1, p. 52-58, 1972.

XIA, J.Q., LOFSTEDT, R.M., YASON, C.V., et al. Detection of bovine herpesvirus 1 in the semen of experimentally infected bulls by dot-blot hybridization, polymerase chain reaction and virus isolation. Research in Veterinary Science, v. 59, n. 2, p. $183-185,1995 \mathrm{a}$

XIA, J.Q., YASON, C.V., KIBENGE, F.S.B. Comparison of dot blot hybridization, PCR, and virus isolation for detection of BHV-1 in artificcially infected bovine semen. Canadian Journal of Veterinary Research, v. 59, n. 2, p. 102-109, $1995 b$.

YASON, C.V., HARRIS, L.M., McKENNA,P.K., et al. Establishment of conditions for detection of BHV-1 by PCR using primers in the thymidine kinase region. Canadian Journal of Veterinary Research, v. 59, n. 2, p. 94-101, 1995.

Ciência Rural, v. 29, n. 2, 1999. 